\title{
Burden of functional gastrointestinal disorders in a surgical clinic in Sri Lanka
}

\author{
Amal Priyantha, Suchintha Tillakaratne ${ }^{1}$, Pulasthi Kanchana Wataraka Gamage ${ }^{2}$, Suresh Nagalingam, \\ Enoka Peiris Dombagahapathirage ${ }^{3}$ \\ ${ }^{1}$ Professorial Surgical Unit, North Colombo Teaching Hospital, Ragama, Sri Lanka \\ ${ }^{2}$ Teaching Hospital, Kandy, Sri Lanka \\ ${ }^{3}$ National Cancer Institute, Maharagama, Sri Lanka
}

Keywords: Follow up; functional gastrointestinal disorders; Rome III; symptoms

\begin{abstract}
\section{Introduction}

Making a positive diagnosis of functional gastrointestinal disorders based on the patterns of symptoms allows the clinician to manage the patients without further investigations (treat and test strategy) to exclude an organic disorder (test and treat strategy).
\end{abstract}

The objectives were to diagnose and classify the functional gastrointestinal disorders according to Rome III criteria among the patients attending to a Gastrointestinal surgery clinic and to assess the effectiveness of the treat and test strategy.

\section{Methodology}

In a prospective study data were collected from consecutive patients who were likely to have functional gastrointestinal disorders. Diagnosis and classification were performed by an interviewer administered Rome III questionnaire. They were then treated according to their symptoms and considered for further investigations or only follow up depending on the response.

\section{Results}

There were 103 patients with "likely FGID" among 665 clinic patients (15.4\%) over six-month period. Eighty-two patients fulfilled the Rome III criteria (79.6\%). Forty-nine patients had single FGID (59.7\%) whereas 33(40.2\%) patients had overlap symptoms. Eighty-one patients $(78.6 \%)$ have been followed up for a mean duration of 12.3 months. Sixty-five patients $(80.2 \%)$ underwent investigations whereas sixteen patients had only followed up (19.8\%). Three patients (3.7\%) were diagnosed with organic illness during the follow up.

Correspondence: Amal Priyantha

E-mail: amalpm2003@yahoo.com

(iD https://orcid.org/0000-0001-5482-0408

Received: 11-04-2020 Accepted: 27-08-2020

DOI: http://doi.org/10.4038/sljs.v38i2.8737

\section{Conclusion}

Functional gastrointestinal disorders are common among our patients. Making a positive diagnosis initially can avoid unnecessary investigations. Close follow up is necessary to avoid false negatives if empirical treatment (algorithmic approach) is used in the initial management.

\section{Introduction}

Functional gastrointestinal disorders (FGID) are a group of chronic disorders of the gastrointestinal (GI) tract arising from multiple factors including gut mucosa and microflora, enteric nervous system and signalling within the brain and spinal cord. They are grouped under the "functional" disorders since there is no demonstrable pathophysiological or biochemical abnormality despite having various symptoms. In the absence of any physical signs and biomarkers, diagnosis and classification of FGID are based on the study of symptom patterns and few basic investigations where relevant and available. For this purpose, Rome classification is very useful since it is a standardized and internationally recognized symptom-based classification. Further, Rome criteria enable the clinician to make a specific diagnosis rather than labelling the patient as having a functional disorder of the GI tract.

This will also provide the clinician with an opportunity to inform the patient of our current understanding of FGID and tailor the available therapeutic options according to the patients' requirements. Most of the studies published in literature address specific FGID such as Irritable Bowel Syndrome (IBS) or Functional dyspepsia (FD) [1]. Other types of FGID have not been investigated as often. Only a few studies surveyed and classified multiple FGID [1].

These studies are either population based or limited to a specific group of population [1]. Use of Rome criteria in a clinical setting not only can make the diagnostic process more efficient but also reduce the unnecessary diagnostic procedures and related costs. This is especially true in a third world country like us where health resources are scarce. The usefulness of symptom-based criteria to make a positive diagnosis of specific FGID $\mathrm{s}$ in clinical practice has been studied. Majority of them have focused on detecting IBS among the patients with lower GI symptoms or diagnosing 
functional dyspepsia among the patients with upper GI symptoms [2,3]. There are several studies on the spectrum of the FGID diagnosed by Rome criteria in tertiary care centres [4].

\section{Objectives}

This study aimed to establish a positive clinical diagnosis and analyse the spectra of functional gastrointestinal disorders (FGID) in a Gastrointestinal surgery outpatient clinic using Rome III criteria and to assess the effectiveness of the treat and test strategy in reducing the number of patients undergoing investigations.

Patients who visited the outpatient clinic of the Gastrointestinal surgery clinic (a tertiary referral centre) were investigated. Ethical clearance for this study was obtained from the ethical committee of the Hospital. Written consent was obtained from the patients after explaining the nature of the study. A detailed history taking, and thorough clinical examination was performed and those with "likely FGID" were recruited. Patients who had alarm signs or diagnosed with the organic disease were excluded. The Rome III Diagnostic questionnaire for adult functional GI disorders was used among patients with "likely FGID" as an interviewer administered questionnaire by two investigators who were familiar with it. The questionnaire was translated into one of the two native languages by the interviewer and the answers were recorded in the printed form. It was tested in 10 patients prior to the study to assess the clarity, understandability and the appropriateness of the translation. Those in whom the diagnosis of FGID was made were reassured and treated according to their symptoms. They were then reassessed after two to four weeks. Patients who did not respond to the treatment were considered for further investigations if deemed necessary. Responders were followed at regular intervals up to one year.

Since the oesophageal PH monitoring and manometry were not freely available in our institution, the differentiation between the Gastroesophageal reflux disease (GERD) and functional heartburn was based on the response to proton pump inhibitors (PPI).

\section{Statistical analysis}

Continuous variables were presented as mean \pm standard deviation, and categorical data were presented as numbers and percentages.

\section{Results}

\section{Demography}

Total of 665 patients was seen in our clinic for over 6 months. After excluding patients with the organic disorder and alarm features, $103(15.4 \%)$ patients were recruited for the study.
Demographic criteria of these patients are seen in table 1.

Presenting symptoms and the duration of symptoms of the study group are shown in table -2 . Eighty-two patients fulfilled Rome III criteria (79.6\%). Prevalence of deferent FGIDs is listed in table 3. Forty-nine patients had single FGID $(59.7 \%)$ whereas $33(40.2 \%)$ patients had overlap symptoms (table -4$)$. The two most commonly overlapping symptoms were Functional bloating and Unspecified functional bowel disorder (FBD) ( $\mathrm{n}=6 ; 7.3 \%)$.

\section{Follow up}

Follow up data of 81 patients ( $78.6 \%$ ) were available for the analysis. Mean follow up duration was 12.3 months $( \pm 6.4)$ ). Sixty-five patients (80.2\%) underwent Endoscopic procedure at some stage whereas sixteen patients had only followed up $(19.8 \%)$.

\section{Endoscopy}

Out of the 65 patients who underwent Endoscopy, 25(30.9\%) had already undergone an Endoscopic procedure (Upper GI or Lower GI) at the time of presentation and further 40(49.3\%) patients underwent Endoscopy during the course (Table -6). Forty-seven patients who underwent upper gastrointestinal (GI) Endoscopy one patient (2.1\%) had erosive esophagitis and 10 patients $(21 \%)$ had a hiatal hernia. Twenty-four patients (29.6\%) have undergone lower GI endoscopy and there were Colorectal $(\mathrm{n}=1 ; 4.1 \%)$ cancer, Chron's disease $(\mathrm{n}=1 ; 4.1 \%)$ and Diverticula $(\mathrm{n}=1 ; 4.1 \%)$ among them.

\section{Imaging}

Besides 42 patients underwent imaging (Ultrasound Scan 41, and Computerized Tomography (CT) scan $(n=01)$ of the abdomen. There were four patients with Gall stones and one patient with 'Fatty Liver' among them.

\section{Other assessment}

All five patients with the sensation of a lump in the throat have been referred by the ENT surgeons since they found no abnormality. Six patients with heartburn or epigastric pain were assessed by the Cardiologist to exclude ischaemic heart disease though none of them had abnormal findings. No abnormality was found among the 3 female patients who presented with abdominal pain (other sites) and were assessed by the Gynaecologist. Out of the two patients seen by the Psychiatrist, one patient was diagnosed with Depression.

\section{Organic illnesses}

During follow up (Table - 5) two patients were diagnosed with organic illnesses. Both presented with a history of epigastric pain of 03 months duration. However, they later underwent lower GI endoscopy since there was a history of 
Table 1. Demographic criteria of the study population

\begin{tabular}{|l|l|l|}
\hline \multirow{2}{*}{ Age } & Mean & SD \\
\cline { 2 - 3 } & 45.2 & 13.2 \\
\hline \multirow{3}{*}{ Gender } & Male -47 & FM -56 \\
& $(45.6 \%)$ & $(54.3 \%)$ \\
\cline { 2 - 3 } & FM : M & $1.1: 1$ \\
\hline Total & 103 \\
\hline
\end{tabular}

Table 2. Presenting symptoms and duration

\begin{tabular}{|l|c|c|}
\hline \multicolumn{1}{|c|}{ Symptom } & $\begin{array}{c}\text { Number of } \\
\text { patients }\end{array}$ & $\begin{array}{c}\text { Mean } \\
\text { duration (SD] }\end{array}$ \\
\hline Abdominal pain (other sites) & 38 & $37.9(62.4)$ \\
\hline Epigastric pain & 22 & $49.5(64.9)$ \\
\hline Abdominal distension & 21 & $19.5(26.4)$ \\
\hline Change of bowel habits & 09 & $43.9(56.2)$ \\
\hline Lump in the throat & 05 & $9.8(7.6)$ \\
\hline Belching & 04 & $79.2(64.1)$ \\
\hline Heart burn & 03 & $6.6(7.6)$ \\
\hline Nausea & 01 & 03 \\
\hline
\end{tabular}

Table 3. Prevalence of functional gastrointestinal disorders

\begin{tabular}{|c|c|c|}
\hline Diagnosis & Total & $\%$ \\
\hline Functional bloating & 40 & 48.7 \\
\hline Unspecified Excessive Belching & 20 & 24.3 \\
\hline Unspecified FBD ${ }^{2}$ & 34 & 39.6 \\
\hline IBS- C & 1 & 1.2 \\
\hline IBS- D & 1 & 1.2 \\
\hline IBS- M & 1 & 1.2 \\
\hline IBS- $O$ & 1 & 1.2 \\
\hline Functional Diarrhoea & 1 & 1.2 \\
\hline Functional Heart Burn & 7 & 8.4 \\
\hline Functional Globus & 5 & 6 \\
\hline FAPS $^{b}$ & 3 & 3.6 \\
\hline Functional Chest pain & 1 & 1.2 \\
\hline Functional Dysphagia & 1 & 1.2 \\
\hline EPS $^{c}$ & 1 & 1.2 \\
\hline Idiopathic Nausea & 4 & 4.8 \\
\hline Functional vomiting & 1 & 1.2 \\
\hline Cyclical Vomiting & 1 & 1.2 \\
\hline PPDS $^{d}$ & 5 & 6 \\
\hline Functional Rumination & 1 & 1.2 \\
\hline
\end{tabular}

a- Functional bowel disorder; b- Functional abdominal pain syndrome;

c- Epigastric pain syndrome; d- Postprandial distress
Table 4. Overlap symptoms

\begin{tabular}{|c|c|c|}
\hline $\begin{array}{c}\text { Number of symptoms in a } \\
\text { cluster }\end{array}$ & $\begin{array}{c}\text { Number of } \\
\text { clusters }\end{array}$ & $\begin{array}{c}\text { Number of } \\
\text { patients (\%) }\end{array}$ \\
\hline 2 & 12 & $21(25.6 \%)$ \\
\hline 3 & 7 & $11(13.4 \%)$ \\
\hline 4 & 1 & $1(1.2 \%)$ \\
\hline
\end{tabular}

Table 5. Follow up of patients

\begin{tabular}{|l|c|c|}
\hline \multicolumn{1}{|c|}{ Results } & Number & $\%$ \\
\hline Cured with treatment & 14 & $17.2 \%$ \\
\hline $\begin{array}{l}\text { Initially responded but experienced } \\
\text { recurrent of symptoms }\end{array}$ & 47 & $58 \%$ \\
\hline Experienced different symptoms & 03 & $3.7 \%$ \\
\hline No response to treatment & 14 & $17.2 \%$ \\
\hline Diagnosed with organic illness & 03 & $3.7 \%$ \\
\hline
\end{tabular}

change of bowel habits on systemic review. One of them (a 48year-old male) was diagnosed with carcinoma of the sigmoid colon while the other patient (a 32-year-old female) was diagnosed with Crohn's disease.

Other findings such as Gall stones, 'Fatty Liver", Hiatal hernia and diverticular were regarded as incidental findings since they do not bare clinical relevance to the patients' symptoms.

\section{Discussion \\ Demography}

The age and sex distribution of our study group showed a similar trend when compared with other studies [5, 6]. Mean age of our study group was also comparable (45 to 38 years) to the other similar studies $[4,6.7]$. However, differences were observed in the prevalence and the spectrum of the FGID in our patients. Population based studies on the entire spectrum of the FGID reveal that the prevalence of FGID varies, ranging from $61 \%$ to $36 \%$ among the general population [4].

Other population-based studies have reported a lower incidence of FGID (26.2\%) than this [8] suggesting a wide variation of FGID among deferent populations. Still fewer studies have been conducted in a tertiary care setting. One such study examined the prevalence of FGID among the patients attending the primary clinics and tertiary care hospitals in Korea [9] and FGID was diagnosed in 49.7\% patients. In this study, functional dyspepsia (46.0\%) and irritable bowel syndrome $(40.2 \%)$ were the commonest FGIDs. A similar study examined the prevalence of FGID among patients referred to a Gastroenterology clinic in the UK and found $34.9 \%$ of patients as having an FGID [10]. However, this study is retrospective in nature and being criticized for not using specific diagnostic criteria such as Rome criteria. 
Several other studies have reported FGID in more than $40 \%$ of all new referrals to general gastroenterological outpatient clinics $[11,12]$. Our study was conducted in a Gastrointestinal surgery clinic of a tertiary care hospital and the prevalence of FGID was $12.3 \%$ among them. Low incidence among our patients could have been due to multiple factors including a lower incidence of FGID in our population, small number of cases in this study or because our study is from a GI surgical clinic. Besides, since the diagnosis of FGID also depends on other factors including clinical suspicion [13] we may have underdiagnosed them in our patients.

\section{Spectrum}

Though IBS and FD are the two most frequently studied FGIDs and presumed to be the commonest in the general population, published data investigating the entire spectrum of the FGIDs suggests that deferent groups of the population may have deferent leading FGIDs. In a study carried out among military personal in Korea, Nausea and vomiting disorders $(6.93 \%)$ and functional abdominal bloating $(6.39 \%)$ were the two leading FGIDs9. Population based study analysing the spectrum of the FGID among Taiwanese population [5] revealed that the Unspecified FBD was the most prevalent $(8.9 \%)$ followed by FD (5.3\%). In Australia, Functional Heartburn (10.4\%), IBS (8.9\%) and functional incontinence $(7.6 \%)$ were the commonest symptoms in a population-based study [6]. Similarly, the most prevalent FGID among tertiary referrals in South China were FD (54.6\%), IBS (40.7\%) and unspecified functional bowel disorder (13.9\%) 4. The two commonest FGIDs in our patients were Functional bloating (48.7\%) and Unspecified FBD (39.6\%). Therefore, it appears as if there is a wide variation in the spectrum of the FGID among the deferent population. Unlike the population-based studies, those conducted in referral centres record higher percentages probably due to the small number of patients.

\section{Symptom overlap}

Symptom overlap seems to be a common phenomenon across most of the published studies. Chinese study4 reported overlapping symptoms among $(50.3 \%)$ of patients. In this study, functional bloating had no overlap. In comparison, $40.2 \%$ of our patients reported symptom overlap and Functional bloating was the commonest overlapping FGID. In the same study, 37.4\% had two coexisting FGID, $8.9 \%$ had three coexisting FGID and $4.0 \%$ had more than three coexisting FGID. In our study $25.6 \%$ had two, $13.4 \%$ had three and $1.2 \%$ had four overlapping FGID.

\section{Economic aspect}

The economic impact of FGID could be considerable given the high prevalence of the condition. This will create increased budgetary constraints, especially within the healthcare system in a developing country like us. Unfortunately, no such cost analysis has been done on the entire spectrum of the FGID according to our knowledge. Most of the cost analysis has been done on IBS and FD. A Danish study compared the diagnosis of IBS by exclusion with a positive clinical diagnosis using Rome criteria in a primary care setting. The total cost of diagnosing IBS with the minimum number of investigations was $\$ 913.59$ compared to $\$ 50.11$ for clinical diagnosis supported few diagnostic investigations such as full blood count and inflammatory markers [14]. This study concluded that diagnosing IBS adhering to clinical findings with a normal full blood count and inflammatory markers in the absence of alarm features could significantly reduce the cost without significant detriment to the patient. Several other studies also have confirmed the non-inferiority of the positive diagnostic approach in IBS [15]. The study conducted among patients with dyspepsia in Brazil concluded that diagnosis by exclusion may not be suitable for developing countries with scarce resources. They also concluded that empirical treatment for patients without alarm signs especially those who are below the cancer age group may be the best approach for managing undiagnosed dyspepsia [16]. In this study, FD was diagnosed using Rome III criteria [17].

In our study, having studied the entire spectrum of the FGID we were able to manage almost one fifth (19.8\%) of the patient without investigations using a treat and test strategy. This is a considerable saving to a health care system in a developing country like us. However, like in Korean study [10] 24 hours, oesophageal $\mathrm{pH}$ monitoring was not routinely performed to diagnose functional heartburn in this study.

\section{Organic diseases and alarm symptoms}

It is well known that organic disease can co-exist with FGID [18]. In contrast to diagnosis by exclusion, diagnosis of FIGD based on symptoms needs alarm symptoms to exclude patients with possible organic illnesses. Several studies have addressed the validity of alarm symptoms in excluding organic disease among patients with symptoms of FGID. The focus of these studies has mainly been either IBS, dyspepsia or both $[2,19,20]$. Though most of them have shown that the alarm futures are useful in excluding the organic causes [21, 22] contradictory results also could be found in the literature [23]. Very few studies have reported organic diseases in a study like this. A study from Australia reported six patients with organic disease in a similar algorithm-based study among 110 (5.4\%) patients. Among them were two patients with malignancy. Others were diagnosed with inflammatory bowel disease $(n=2)$ and one patient each with pancreatic insufficiency, reflux esophagitis and dietary iron deficiency [7]. Among the 103 patients in our study group, 03 patients were found to have organic causes $(3.7 \%)$. Two patients who 
were diagnosed with colon cancer and ulcerative colitis. Both presented with epigastric pain which could have been investigated with Gastroscopy. In both instances, colonoscopy was undertaken since they reported a change of bowel habits at the subsequent visits. This highlights the importance of following up patients if empirical treatment (algorithmic approach) is used in the initial management of FGID especially in tertiary care hospitals.

\section{Symptom evolution}

At the end of the follow-up period, $17.2 \%$ of patients did not have symptoms and $58 \%$ of patients experienced recurrent symptoms. Long term studies on FGID reveal that the persistent symptoms may either change or fluctuate in severity and the patients rarely become symptom-free $[18$, 24]. A study among children found complete improvement in $60.1 \%$, no improvement in $10.1 \%$ and recurrence in $35.7 \%$ of the patients whereas $11.65 \%$ of patients reported new symptoms [25]. In our study, $3.7 \%$ of the patients reported deferent symptoms during the follow up. In a prospective cohort study conducted in the USA, approximately $20 \%$ had the same symptoms, $40 \%$ had no symptoms, and $40 \%$ had different symptoms after 12-year follow-up [18]. It is difficult to ascertain whether wide variation in symptom free and symptom recurrence among the deferent population is due to the disease characteristics or due to variation in treatment approach among these studies.

\section{Conclusion}

There is a variable but significant number of patients with Functional gastrointestinal disorders among deferent referral centres. Making a positive diagnosis using Rome III criteria can avoid unnecessary investigations and reduce the usage of health care resources. The predominant type of the FGID and overlap may vary among deferent patient populations. Given the low reliability of alarm symptoms in excluding organic diseases, close follow up is necessary to avoid false negatives if empirical treatment (algorithmic approach) is used in the initial management of FGID.

All authors disclose no conflict of interest. The study was conducted in accordance with the ethical standards of the relevant institutional or national ethics committee and the Helsinki Declaration of 1975, as revised in 2000 .

\section{References}

1. Fang-Yuan Chang MD, Po-Hon Chen,Tzee-Chung Wu, WenHarn Pan, Hsing-Yi Chang, Shin-Jiuan et al. Prevalence of functional gastrointestinal disorders inTaiwan: questionnairebased survey for adults based on the Rome III criteria. Asia Pac J Clin Nutr 2012; 21 (4), 594-600.
2. Lea R, Hopkins V, Hastleton J, Houghton LA, Whorwell PJ. Diagnostic criteria for irritable bowel syndrome: utility and applicability in clinical practice. Digestion. 2004; 70:210-213. https://doi.org/10.1159/000082891

3. Hyuk Lee, Hye-Kyung Jung, Kyu Chan Huh. Current status of functional dyspepsia in Korea. Korean J Intern Med 2014;29:156-165 https://doi.org/10.3904/kjim.2014.29.2.156

4. Xiong LS, Shi Q, Gong XR, Cui Y, Chen MH. The spectra, symptom profiles and overlap of Rome III functional gastrointestinal disorders in a tertiary center in South China J Dig Dis. 2014 Oct; 15(10):538-44.

https://doi.org/10.1111/1751-2980.12178

5. Chang FY, Chen PH, Wu TC et al. Prevalence of functional gastrointestinal disorders inTaiwan: questionnaire-based survey for adults based on the Rome III criteria. Asia Pac J Clin Nutr 2012; 21 (4), 594-600.

6. Boyce PM, Talley NJ, Burke C, Koloski NA. Epidemiology of the functional gastrointestinal disorders diagnosed according to Rome II criteria: an Australian population-based study. Internal Medicine Journal, 2006; 36; 28-36. https://doi.org/10.1111/j.1445-5994.2006.01006.x

7. Ecushla C Linedale, Muhammad A Shahzad, Andrew R Kellie et al. Referrals to a tertiary hospital: A window into clinical management issues in functional gastrointestinal disorders. JGH Open, 2017;(1), 84-91. https://doi.org/10.1002/jgh3.12015

8. Wu W, Guo X, Yang Y, et al. The Prevalence of Functional Gastrointestinal Disorders in the Chinese Air Force Population. Gastroenterology Research and Practice, 2013; 1155-61. https://doi.org/10.1155/2013/497585

9. Park JM, Choi MG, Cho YK et al, Functional Gastrointestinal Disorders Diagnosed by Rome III Questionnaire in Korea. J Neurogastroenterol Motil. 2011; 17(3): 279-286. https://doi.org/10.5056/jnm.2011.17.3.279

10. Shivaji UN, Ford AC. Prevalence of functional gastrointestinal disorders among consecutive new patient referrals to a gastroenterology clinic. Frontline Gastroenterology 2014; 5:266271. https://doi.org/10.1136/flgastro-2013-100426

11.Corazziari E. Definition and epidemiology of functional gastrointestinal disorders. Best Pract Res Clin Gastroenterol 2004;18:613-31. https://doi.org/10.1016/j.bpg.2004.04.012

12.Hungin AP, Whorwell PJ, Tack J, Mearin F. The prevalence, patterns and impact of irritable bowel syndrome: an international survey of 40,000 subjects. Aliment Pharmacol Ther 2003; 17:64350. https://doi.org/10.1046/j.1365-2036.2003.01456.x

13. Mearin F, Malfertheiner P. Functional Gastrointestinal Disorders: Complex Treatments for Complex Pathophysiological Mechanisms. Dig Dis. 2018 Mar; 35(1): 1-4.

https://doi.org/10.1159/000485407

14. Spiegel BMR, Farid M, Esrailian E, Talley J, Chang L. Is irritable bowel syndrome a diagnosis of exclusion?: a survey of primary care providers, gastroenterologists, and IBS experts. Am J Gastroenterol 2010; 105: 848-58. https://doi.org/10.1038/ajg.2010.47 
15.Begtrup LM, Engsbro AL, Kjeldsen J et al. A positive diagnostic strategy is non-inferior to a strategy of exclusion for patients with irritable bowel syndrome. Clin Gastroenterol Hepatol 2013; 11 (8) : 956-62. https://doi.org/10.1016/j.cgh.2012.12.038

16.Jacob JF, Fernando MS, Tomás NR et al. Endoscopic findings in uninvestigated dyspepsia. BMC Gastroenterology 2014, 14:1926. https://doi.org/10.1186/1471-230X-14-19

17.Drossman DA, The functional gastrointestinal disorders and the Rome III process. Gastroenterology, 2006:130 ( 5) 1377-90. https://doi.org/10.1053/j.gastro.2006.03.008

18. Halder SLS, Locke GR, Schleck CD, Zinsmeister AR, Melton LJ,Talley NJ. Natural history of functional gastrointestinal disorders: a 12-year longitudinal population-based study. Gastroenterology, 2007; 33: 799-807 https://doi.org/10.1053/j.gastro.2007.06.010

19.Mearin F, Lacy BE. Diagnostic criteria in IBS: useful or not? Neurogastroenterol Motil(2012) 24, 791-801. https://doi.org/10.1111/j.1365-2982.2012.01992.x

20.Whitehead WE, Palsson OS, Thiwan SIM, et al. Development and validation of the Rome III diagnostic questionnaire. In: Drossman, DA. Corazziari, E.; Delvaux, M.; Spiller, RC.; Talley, NJ.; Thompson, WG.; Whitehead, WE. Rome III: The Functional Gastrointestinal Disorders. 3rd ed. McLean, Virginia: Degnon Associates; 2006 ; 835-853.
21. Whitehead WE, Palsson OS, Feld AD, Levy RL, Von KM, Turner MJ, Drossman DA. Utility of red flag symptom exclusions in the diagnosis of irritable bowel syndrome. Aliment Pharmacol Ther. 2006; 24:137-146. https://doi.org/10.1111/j.1365-2036.2006.02956.x

22.Meineche-Schmidt V, Jorgensen T: "Alarm symptoms" in patients with dyspepsia: a three year prospective study from general practice. Scand J Gastroenterol 2002, 37:999-1007. https://doi.org/10.1080/003655202320378167

23. Vakil N, Moayyedi P, Fennerty MB, Talley NJ: Limited value of alarm features in the diagnosis of upper gastrointestinal malignancy: systematic review and meta-analysis. Gastroenterology 2006, 131:390-401.

https://doi.org/10.1053/j.gastro.2006.04.029

24.Olafsdottir LB, Gudjonsson H, Jonsdottir HH, Thjodleifsson B. Stability of the irritable bowel syndrome and subgroups as measured by three diagnostic criteria - a 10-year follow-up study. Aliment. Pharmacol. Ther. 2010; 32(5): 670-80. https://doi.org/10.1111/j.1365-2036.2010.04388.x

25.Madania S, Parikhb S, Madanic RS, Krasaelapa A. Long-Term Study of Children With ROME III FunctionalGastrointestinal Disorders Managed Symptomatically in a Biopsychosocial Model. Gastroenterol Res. 2017;10(2):84-91.

https://doi.org/10.14740/gr798w 